\title{
A REVIEW ON DESIGN OF AIR CONDITIONING SYSTEM OF THE SCHOOL FOR BETTER INDOOR AIR QUALITY
}

\author{
Parth.J.Makadia ${ }^{1}$, Shubham.U.Nalawade ${ }^{2}$, Siddhesh.S.Jadhav ${ }^{3}$, Akshay.L.Gawade ${ }^{4}$ \\ Shashikant.S.Goilkar ${ }^{5}$ \\ Undergraduate Students, Department of Mechanical Engineering, Finolex Academy of Management and \\ Technology Ratnagiri, Maharashtra, India. ${ }^{1,2,3,4}$ \\ makadiaparth45@gmail.com \\ Assoicate Professor, Department of Mechanical Engineering, Finolex Academy of Management and \\ Technology Ratnagiri, Maharashtra, India. ${ }^{5}$ \\ $* * *$
}

\begin{abstract}
Better climatic condition inside the educational institute premises is nowadays becoming one of the effective tools for improvement of teaching learning process. Provision of Air conditioning system with better indoor quality of air can help students to concentrate during their learning as well as can help the teachers while teaching. In many education systems it has been observed that in order to make sure students are getting most out of their education, school should have air conditioning system in classrooms to optimize the learning. According to a study, when a classroom is too warm or cold, the brain doesn't focus on learning. Instead, it tries to keep the body cool or warmed up as per the need. Air conditioning creates better air quality in the classroom. It filters the air and clears the toxins from the environment. This paper reviews various aspects related air conditioning system to achieve better indoor air quality while designing the air conditioning system based on American Society of Heating, Refrigerating and Air-Conditioning Engineers (ASHRAE) guidelines.
\end{abstract}

Keywords- $H V A C, A S H R A E, A D V, A H U, D H U$.

\section{INTRODUCTION}

Air-conditioning System consists of group of components or equipment connected in series to control the environmental parameters. The economic liberalization policy and subsequent entry of multinational companies in Indian market resulted in sprouting of many advanced air-tight glazed buildings throughout major cities of the country. All these modern buildings employ air conditioners to control their indoor environments. So, the project is focusing on the practical issue and problem of the day, which will make our approach industry-pro and will develop ability to solve real life problem. As per research carried out by various HVAC engineers, it is found that the human body feels comfortable at 25-degree Celsius temperature, $50 \%$ relative humidity and with sufficient flow of clean air.

Due to the various sources of heat temperature inside the room becomes very high relative humidity can also be high. Further, there can also be less be less flow of air inside the room. All these factors lead to creation of highly uncomfortable conditions inside the room. The Air Conditioner removes all the heat that is generated inside the room and maintains the temperature of 20degree Celsius. It also removes the excess amount of moisture from the air and maintains the relative humidity of $50 \%$. The Air Conditioner has fan that produces necessary flow of air and filter removes all the dust and dirt particles from the air. 


\section{AND ENGINEERING TRENDS}

\section{CENTRALIZED AND DECENTRALIZED AC SYSTEM}

Two types of Air Conditioning systems generally exist, namely centralized and decentralized AC system. Centralised AC system reflect advance and efficient energy usages, they consume less energy with better service. The main advantages of centralised AC system is they can satisfy the cooling requirement for a multiple building at a time centralise AC system required low power as compare to split AC system. However, decentralised and centralised AC systems have their own advantages and disadvantages. Decentralized AC system users have greater flexibility in controlling the $\mathrm{AC}$ terminals according to their requirements [1].

Centralised are applied in all cases however level of centralisation is relatively different. AC system can be considered three heat transfer segments namely,

1) The heat transfer process between $\mathrm{AC}$ terminals and indoor environment.

2) Chilled water heat distribution process between refrigerating machines and $\mathrm{AC}$ terminals.

3) The cooling water heat distribution process between refrigerating machines and he cooling sides.

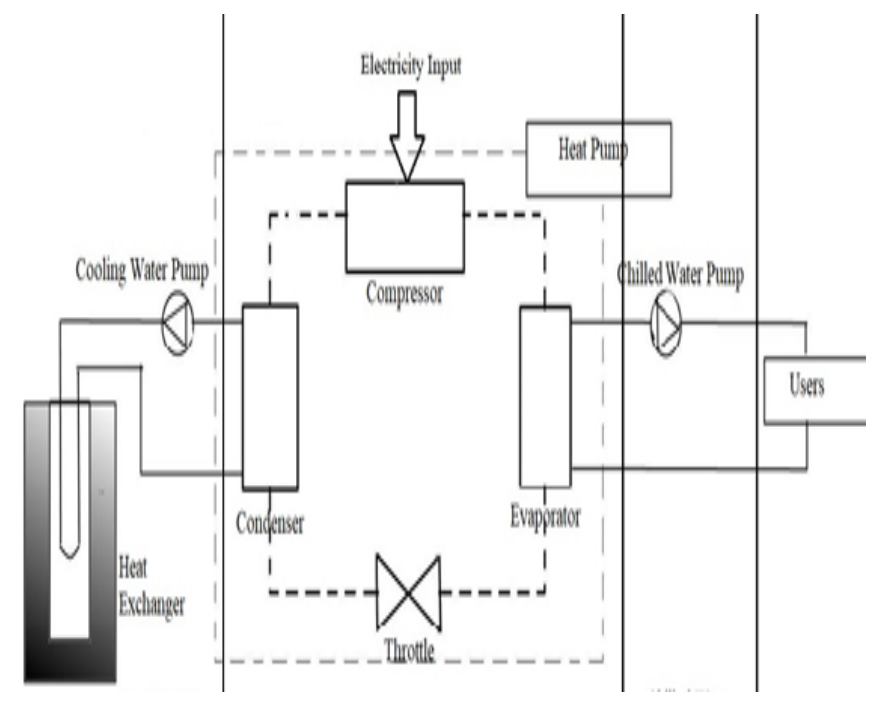

Fig.1. Schematic diagram of Air Conditioning system
These three segments have three cases namely,

Case 1- Centralised refrigerating machines and distribution system of chilled water and cooling water, users can not adjust the AC terminals.

Case 2- Centralised refrigeration machines and distribution system of chilled water, in this case users can adjust the $\mathrm{AC}$ terminals.

Case 3- Decentralized refrigerating machines, centralised distribution system of chilled water and cooling water in this case users can adjust the $\mathrm{AC}$ terminals.

\section{INTERNAL ENVIRONMENTAL QUALITY}

Internal environmental quality (IEQ) has focused on a radially measurable aspect of heat, light, air quality and sound and although impressive individual sense impacts have been identified. Thus, three design principles have been used to suggest and structure the factors to be considered, namely

1. Naturalness

2. Individualisation

3. Simulation

Within this structure the full range of reverent factors (e.g. light, layout) that might be element of a good design for a particular school can be grouped, so providing clear and balance set of factors to be tested [2].

\section{Naturalness:}

This principle relates to the environmental parameter that are required for physical comfort, these are light, sound, temperature, air quality.

\section{Individualisation:}

This principle relates to well the classroom meets the needs of particular group of children, it is made up of flexibility and connection.

\section{Simulation:}

This principle is related to how exciting and vibrant the classroom is. It has two parameters complexity and colour. 


\section{|| Volume 5 || Issue 12 || December 2020 || ISSN (Online) 2456-0774 INTERNATIONAL JOURNAL OF ADVANCE SCIENTIFIC RESEARCH}

\section{AND ENGINEERING TRENDS}

\section{INDOOR AIR QUALITY CONTROL FOR HUMAN HEALTH}

With the improvement of standard of Living air conditioning has widely been applied. However with problems associated with air conditioning system \& indoor air quality appears more frequently. Indoor air environment must meet the requirement of thermal comfort. Thermal factor is affected by many factors mainly include air temperature air humidity, air velocity; mean radiant temperature, human clothing and activity levels.

A comfortable and healthy air indoor air environment is favourable to occupants. Indoor thermal comfort has been improved greatly due to development of $\mathrm{AC}$ systems. Many researchers have widely investigated the composition of pollutants, sources, physical \& chemical characteristics and effect on human health. The composition of indoor pollutants is quite complex. It is also uncertain that the impact of exposure amount and exposure time on human health. Only if these problems are resolved than indoor air environment be controlled accurately and reasonably.

Outstanding AC helps to improve indoor air environment. Indoor air purification is an important method of removing indoor pollutants under the circumstances that the ventilation and the control of pollution are possible. The methods of indoor air purification mainly include filtration, adsorption, NTP. However, this method has its advantage due to complexity of indoor pollutants such as poor purification effects, high energy consumption [3].

The combination purification devices with excellent performance also need to be designed \& optimized based on result of foundational results.

\section{A. Gaseous Pollutants:}

There several types gaseous pollutants mainly causing effects on air conditioning system. The gaseous pollutants can be divided in to two sub groups that are Primary gaseous pollutants and Secondary gaseous pollutants [4].

\section{1) Primary gaseous pollutant:}

Primary gaseous pollutants mainly include $\mathrm{CO}_{2}, \mathrm{CO}$, $\mathrm{SO}_{2}, \mathrm{NOX}, \mathrm{O}_{3}$, radon and VOCs. Chemical materials have widely been used indoors recently. The chemical materials can release many kinds of chemical pollutants at room temperature, and VOCs are the main composition of these chemical pollutants. VOCs can cause many symptoms, such as headache; eye, nose, and throat irritations; dry cough; dizziness and nausea; tiredness. VOCs also have bad effects on respiration systems, blood vessel systems, and nerve systems. The material like carpet, man-made board, fine board, agglutination board, composite floor, cork, paint, adiabatic layer, and heat pipeline are a main source of VOCs.

The dimensionless emission rate of VOCs is only a function of the ratio of mass transfer Biot number to the partition coefficient and of mass transfer Fourier number. For the multi-layer materials, the top layer materials strongly delay VOCs emission from the bottom layer materials. The multi-layer materials have a much longer VOCs emission time and a slower VOCs decay rate than the single-layer materials.

\section{2) Secondary gaseous pollutant:}

The mix of pollutants in indoor environments can be transformed as a consequence of chemical reaction. Reaction Between ozone and some unsaturated hydrocarbons is an important source of indoor secondary pollutants which mainly include free radicals, aldehydes, ketones, alcohols, carboxylic acids. Such reactions may have larger impact on IAQ than those that occur in the gas phase because of the large indoor surface to volume ratio.

A major Limitation in evaluating the impact of secondary pollutants is the inability to measure many of the reaction products .Sensory measurements are useful in detecting changes derived from indoor chemistry and changes missed by the Analytical methods routinely used to evaluate indoor air. Indoor secondary pollutants have significant impact on comfort and human health, but the degree of impact and 


\section{|| Volume 5 || Issue 12 || December 2020 || ISSN (Online) 2456-0774 INTERNATIONAL JOURNAL OF ADVANCE SCIENTIFIC RESEARCH}

\section{AND ENGINEERING TRENDS}

the frequency of occurrence are uncertain at present. In addition, many secondary pollutants cannot be measured because of the complexity of composition and it is necessary to improve the measure level.

\section{B. Air distribution mode, Air change and filtration:}

Air distribution mode plays vital role in controlling the pollutants in a clean room which can be divided into-

1) Unidirectional air flow: It gradually squeezes the dirty air and discharges it into return air outlet.

2) Non unidirectional air flow: It dilute the concentration of indoor pollutants by mixing clean air flow sent to room.

Three basic filtration stages are usually incorporated namely: Primary filter, second stage filter (the high efficiency particulate bag filter) and a third stage filter which is the high efficiency particulate filter located at the air supply outlets [5].

\section{Air conditioning system and cold and heat sources}

Standard states that air conditioning system shall ensure the overall control of clean operating room and keep operating the rooms in flexible use. After several improvements Joubert operating room air conditioning system has been formed. This system uses, three stage fans to increase the indoor air circulation to increase ventilation coefficient and to reduce the indoor bacteria. The different operating rooms have different heat and moisture load, so operating room has separate air conditioning unit and each operating room has separate exhaust. The operating room has good and heat insulation and there are heating from indoor lighting, of sunlight and medical equipment heating.

Temperature should be controlled by change of supply temperature without any airflow control; the temperature difference between warm and cool regions should be minimized to decrease airflow drift. There are advocates of both vertical and horizontal laminar airflow systems. For high-contaminated areas, the local velocity should be greater than or at least equal to 0.2 $\mathrm{m} / \mathrm{s}$. The unidirectional laminar airflow pattern is commonly attained at a velocity of $0.45 \pm 0.10 \mathrm{~m} / \mathrm{s}$.

\section{INDOOR AIR QUALITY CONTROL OF A HVAC SYSTEM}

Indoor air quality deals with the content of interior air, could affect health and comfort of building occupants. The quality of the indoor air depends upon a number of factors including the concentrations of a variety of gaseous and particulate pollutants in the indoor air. These air pollutants may enter the building with outside air or may be generated internally. Indoor air quality is therefore influenced by two major components: the amount and quality of outdoor air getting in, and indoor sources of emissions. The influence of outdoor air quality on indoor air quality depends on the air exchange rate. Inadequate air exchange rate causes poor indoor air quality. On the other hand, too much outdoor air results in energy waste for cooling [6].

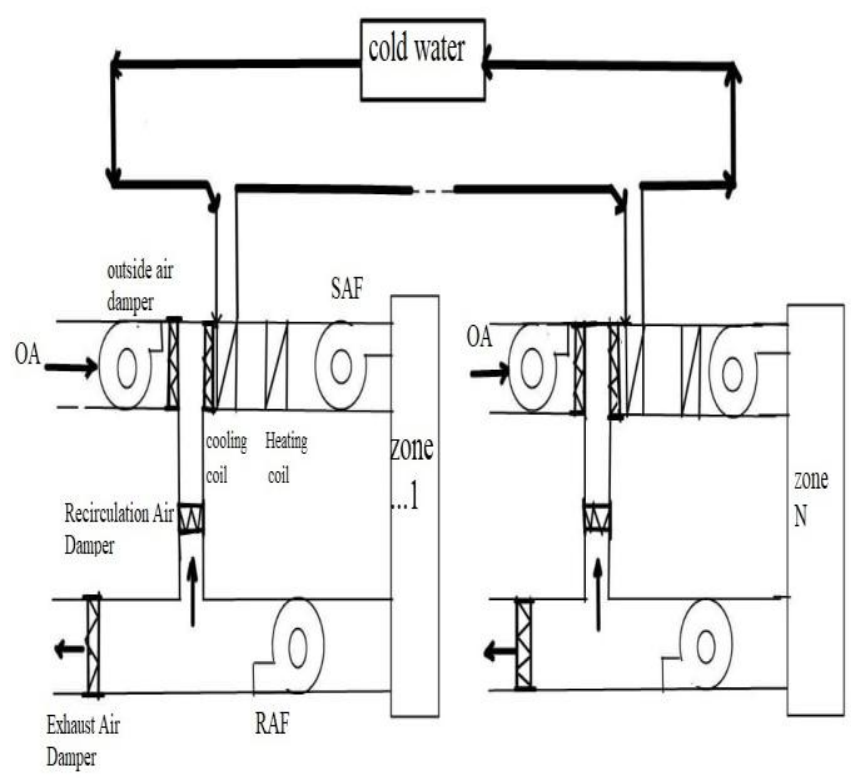

Fig.2. Schematic diagram of a typical HVAC

Figure 2 is a schematic diagram of a typical HVAC system with multiple zones. Many HVAC systems use a central plant to provide hot water $\mathrm{T}_{\text {wo }}$ (e.g. with temperature of $32^{\circ} \mathrm{C}$ ) for heating purposes and cold water (e.g. with temperature of $18^{\circ} \mathrm{C}$ ) for cooling 


\section{|| Volume 5 || Issue 12 || December 2020 || ISSN (Online) 2456-0774 INTERNATIONAL JOURNAL OF ADVANCE SCIENTIFIC RESEARCH}

\section{AND ENGINEERING TRENDS}

purposes. The hot (or cold) water from a boiler (or chiller) is pumped along the ductwork and flows into heating (or chilling) coil for heat exchange with cold (or hot) room air and then comes back to the central plant with a slightly lower (or higher) temperature $T_{\text {wi }}$. The air out of the heat exchanger (heating or chilling coil) goes through the supply air fan, down the insulated supply duct into the zone area as supply air (SA) for the zone. The supply air gains/gives up all of its heat from/to the zone to replace the heat that is transferring and leaking through the walls, roofs, etc. Then the air goes through the room and into the return air inlets. Some return air goes outside. The rest of the return air goes through the return air damper into the mixing box and mixes with the outside air.

\section{OPTIMAL DESIGN OF MULTI-ZONE AIR- CONDITIONING SYSTEMS FOR BUILDINGS REQUIRING STRICT HUMIDITY CONTROL}

The air-conditioning systems in buildings where strict space humidity control is required are usually very energy intensive, where significant energy would be wasted if the system is not properly designed and controlled. Conventional design method in such buildings usually selects the air-conditioning systems based on certain cooling load and experiences without comprehensively considering the control strategies involved. The author proposes the method to design AC considering uncertainties for cooling load calculations and adopting the "adaptive full-range decoupled ventilation strategy" (ADV strategy).

The main objective of the proposed design method is to minimize the life-cycle total cost of air-conditioning systems adopting the alternative decision-making criteria. A hybrid genetic algorithm and particle swarm optimization algorism (GA-PSO) is used for design optimization.

Strict space humidity control is required in many applications such as hospitals, manufacturing facilities, pharmaceutical cleanrooms, art galleries, libraries and other commercial facilities. In such applications, design and selection of an appropriate air-conditioning system require that the system meet both sensible and latent loads simultaneously under different possible operational conditions [7].

A. Description of adaptive full-range decoupled ventilation strategy (ADV strategy):

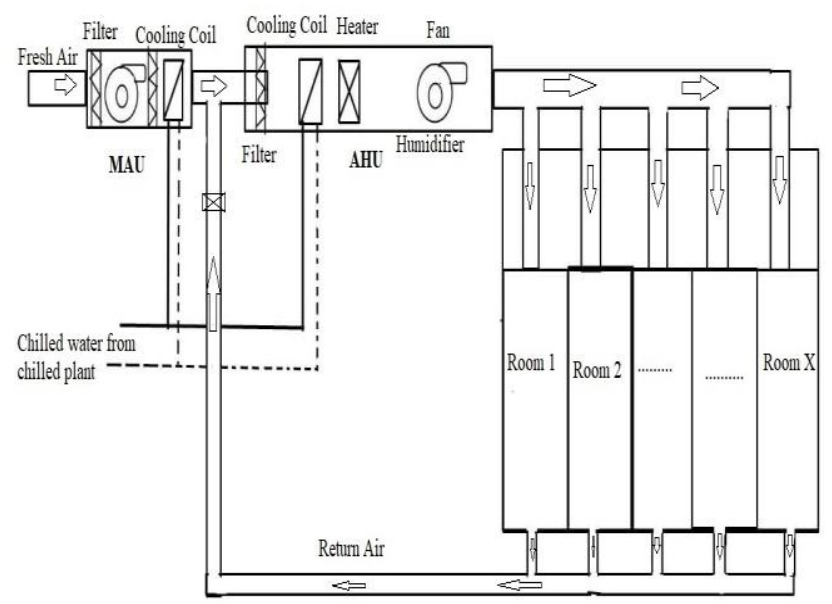

Fig.3. System configuration of a typical airconditioning system

There are existing strategies which are adopted by traditional AC systems that are "Dedicated outdoor air ventilation strategy" (DV strategy) fully decouples cooling and dehumidification by the combined use of make-up air-handling units (MAUs) and air-handling units (AHUs), where the MAU undertakes all indoor redundant latent load and part of the sensible load while the AHUs remove the residual sensible load. In this strategy, the outdoor airflow can be induced higher than its minimum set point. "Partially decoupled control strategy" (PD strategy) is a method that always induces the minimum outdoor airflow and sets MAU outlet air temperature lower than indoor air dew-point. When the indoor latent load is not high, the minimum outdoor airflow is enough for removing all indoor moisture due to the low MAU outlet temperature, which operates like the DV strategy.

Adaptive full range decoupled ventilation strategy (ADV strategy) incorporates the advantages of the PD strategy, the DV strategy and an adaptive economizer, which minimize the energy consumption by compromising properly "inducing more outdoor air" 


\section{|| Volume 5 || Issue 12 || December 2020 || ISSN (Online) 2456-0774 INTERNATIONAL JOURNAL OF ADVANCE SCIENTIFIC RESEARCH}

\section{AND ENGINEERING TRENDS}

and "sub-cooling and reheating process with minimum outdoor airflow" and offers superior energy-efficiency over the full range of internal load and weather conditions.

\section{B. Optimal design under alternative decision-making criteria and its design approach}

In order to make any design affordable the main objective of the optimal design is to ensure the annualized total cost to be minimum.

$\mathrm{TC}_{\mathrm{annual}}=\mathrm{CC}_{\mathrm{annual}}+\mathrm{OC}_{\mathrm{annual}}+\mathrm{MC}_{\mathrm{annual}}+\mathrm{PC}_{\mathrm{annual}}$

Implementation of optimal design approach:

Obtain the sensible and latent cooling load distribution through qualifying the uncertainties of operation factors and calculate the supply air state according to the asynchronous cooling and dehumidification demand of multi zones. Optimize airside components, then estimate the capacity then determine total cost considering all parameters. Check whether the estimated capacities of cooling and heating equipment are as high as needed. Moreover, the given capacities of the cooling \& heating equipment are verified whether can meet the control requirement of the optimal ventilation strategy (e.g. ADV strategy). If not, the near-optimal or other ventilation strategies are adopted to verify whether these methods can meet the control requirements under such cooling \& heating equipment capacities.

\section{DESIGN AND DEVELOPMENT OF THE AIR CONDITINING SYSTEM BY USING OPC UA SPECIFICATIONS AND MODBUS PROTOCOL}

The authors mainly focused on the technological innovations and researches that have been applied to enhance the integration of OPC (Openness, Productivity, and connectivity) Unified Architecture with the traditional air conditioning system so that it become easy to use for a client and also enhances the air conditioning efficiency. In recent years, the application information technology is widely increased in almost every domain. The application focuses on ensuring needs of users to reduce power consumption and providing feature that can make decisions on adjusting parameters of AC [8].

\section{A. OPC and OPC UA}

The OPC (Openness, Productivity and control) Foundation is an independent, non-profit, industry trade association comprised of more than 350 leading automation suppliers worldwide for proposing the specifications and standards for developing industrial software systems which has specifications like OPC DA (Data Access) which have been widely developed and applied for monitoring and control applications in over the word. The OPC foundation today is proposing and developing the new OPC UA (Unified Architecture) specifications to ensure that the industrial software systems can be run on any platform and operating systems such as windows, Linux, UNIX, Android, etc. The research proposed is going to develop the components of OPC UA and apply them to control and monitoring applications in the prototype.

\section{B. Modbus}

MODBUS Protocol is a messaging structure developed by Modicum in 1979, used to establish master slave/client-server communication between intelligent devices. It is standard, truly open and the most widely used network protocol in industrial manufacturing environment. MODBUS devices usually include a Register Map. MODBUS functions operate on register map monitor, configure, and control module I/O.

The characteristics of the device and communication prototype used in the proposed system:

- Sensor SENSIRION measures Temperature 14 bits and humidity 12 bits made in Sweden.

- Integrating temperature, humidity and foggy spot.

- Determining temperature from -20 to +85 degree centigrade, humidity from $0-100 \%$.

- Accuracy $-+2 \%$ for humidity and +-0.3 degree $\mathrm{C}$ for temperature at 25 degree $\mathrm{C}$.

- Port RS485/RS232 and connecting method Modbus RTU/ASCII. 


\section{|| Volume 5 || Issue 12 || December 2020 || ISSN (Online) 2456-0774 INTERNATIONAL JOURNAL OF ADVANCE SCIENTIFIC RESEARCH}

\section{AND ENGINEERING TRENDS}

- Connection: Connecting ports of devices

The system components consist of the following:

- Devices: Sensor device uses Modbus. We use Module Flex 1000 with temperature sensors and humidity sensors.

- Modbus Driver: Use Modbus Driver of N modbus.

- SDK: SDK is provided by Unified Automation, can support some basic functions in OPC UA connection that include all library file such as uabase.lib, uapki.lib, uamodule.lib...

-OPC Server: This OPC server program is a Console application that can connect to Modbus peripherals.

- OPC Client: Client application running on PC will have interactive interface with OPC server and support for parameter updating and parameter adjusting of Air Conditioning Equipment's.

\section{TOOLS FOR HVAC SYSTEM AND DESIGN ANALYSIS}

Tools for pipe/duct sizing are system design tools that consider flow distribution and sizing of liquid/air distribution system (AFT Fathom, DOLPHIN, Duct Calculator, DUCTSIZE, Pipe-Flo, PYTHON, etc.).

Tools for equipment sizing and selection offer HVAC equipment sizing (Carrier HAP, Trane TRACE 700, Energy Plus, etc.). Most sizing tools are based on standard procedures and algorithms established by American Society of Heating Refrigeration and Airconditioning Engineers (ASHRAE), but many are proprietary software products distributed or sold by equipment manufacturers.

Tools for energy performance analysis are designed to predict the annual energy consumption of an HVAC system. Based on a system of equations that define thermal performance of buildings and systems, and with given boundary conditions, operation strategy and controls, these tools perform (hourly or sub-hourly) simulations (Carrier HAP, Trane TRACE 700, DOE-2, e QUEST, Energy Plus, ESP-r, IDA ICE, TRNSYS, HVACSIM+, VA114, SIMBAD, etc.). These tools are typically used to calculate and analyse the full- and part-load performances, to analyse system operation strategy, to compare different design alternatives.

Tools for system optimization are used in conjunction with tools for energy performance analysis. In multiple simulation runs, a set of parameters is optimized according to a given objective function.

Controllers can be associated with high abstraction system models, such as in ESP-r. Controllers can be represented explicitly either models of supervisory control, such as in Energy Plus, or simple models of local control, such as in ESP-r and TRNSYS. More advanced representation of controllers, such as fuzzy logic, are available in MATLAB based tools (SIMBAD), Damola and tools coupled to MATLAB (ESP-r, TRNSYS). These tools are efficient for design and more comprehensive testing of controllers in a simulation setting, as well as for testing and validation of controller design in real time [9].

\section{CONCLUSION}

This paper reviews various aspects of design of air conditioning systems for a particular building of a school under consideration. This work offers significant contribution for developing air conditioning system that pertains to save energy as well as to provide the better indoor air qualities at optimal cost. The two basic Centralized and Decentralized air conditioning systems have been analyzed. The principles of Internal Environment Quality along with various parameters that are influencing IAQs have been analyzed. This work also initiated the study of AC systems integrated with Automation. The method is proposed to obtain optimal inside air along with all indoor air qualities where a specific humidity control is required. In Automated AC systems various electric sensors have been used in order to achieve regulated air flow without any disturbance. Also there are various methods of obtaining regulated air flow like ADV, GS-POV that have been summarized. The various tools for designing HVAC system have been analyzed.

This mainly includes the tools which can predict annual energy consumption of HVAC systems for example e- 


\section{|| Volume 5 || Issue 12 || December 2020 || ISSN (Online) 2456-0774 INTERNATIONAL JOURNAL OF ADVANCE SCIENTIFIC RESEARCH}

\section{AND ENGINEERING TRENDS}

quest, Dolphin, AFT Fathon. So, more attention is needed in this area and lots of work has to be done based in terms of its background, originality, current status, and researches.

\section{NOMENCLATURE}

$\mathrm{TC}_{\mathrm{annual}}=$ annualized total cost $(\$)$,

$\mathrm{CC}_{\text {annual }}=$ annualized capital cost (obtained from according to components capacities),

$\mathrm{OC}_{\mathrm{annual}}=$ annualized operation cost (electricity cost),

$\mathrm{MC}_{\text {annual }}=$ annualized maintenance cost (set as $20 \%$ of annualized capital cost),

$\mathrm{PC}_{\text {annual }}=$ annualized penalty cost

\section{REFERENCES}

[1]. Xin Zhou, Comparative research on different air conditioning systems for a residential building, Frontiers of Architectural Research 2017; Vol.6, pp 4252.

[2]. Peter Barrett, Fay Davies, Yufan Zhang, Lucinda Barrett, The impact of classroom design on pupils learning: Final result of holistic, multi-level analysis, Building and Environment 2015; Vol.89, pp 118-133.

[3]. B.F.Yu, Z.B.Hu, M.Liu, H.L.Yang, Q.X.Kong, Y.H.Liu, Review of research of air-conditioning systems and air quality control for human health, International journal of refrigeration 2009; Vol.32, pp 3-20.

[4]. Prajakta P. Shrimandilkar, Indoor Air Quality monitoring for human health, International journal of morden engineering research (IJMER) 2013; Vol.3, Issue.2, pp 891-897.

[5]. Yunyu Chen, Study of energy saving design and operation of hospital purification air conditioning system, International journal of low carbon technologies 2018; Vol.13, pp 184-190.

[6]. Jiaming Li, Josh wall, Glenn Platt, Indoor Air Quality Control of a HVAC System, Modelling, Identification, Control 2010; vol.25 pp 756-751.
[7]. Chaoqun Zhuang, Shengwei Wang, Rui Tang, Optimal Design of Multi-Zone Air Conditioning Systems for Buildings Requiring Strict Humidity Control, Elsevier, Procedia Engineering (Science Direct) 2019; Vol.158, pp 3202-3207.

[8]. Nguyen Thi Thanh Tu,Design and Development of Air Conditioning System by Using OPC UA Specifications and Modbus Protocol, IEEE 8th Conference on Industrial Electronics and Applications (ICIEA); 2013.

[9]. Marija Trcka, Jan L.M. Hensen, Overview of HVAC system simulation, Automation in Construction (Science Direct) 2010; Vol.19, pp 93-99. 